\title{
Contingency in fear conditioning: A reexamination
}

\author{
H. M. JENKINS and DONALD SHATTUCK \\ McMaster University, Hamilton, Ontario L8S 4K1, Canada
}

\begin{abstract}
The effects on classical fear conditioning of the rate of presentation of the unconditioned stimulus (US) and the contingency between the conditioned stimulus (CS) and the US were examined using the conditioned emotional response procedure with rats. Increases in US rate reduced suppression by the same amount whether the added USs were signaled by CS, thereby maintaining the CS-US contingency, or unsignaled, thereby weakening the CS-US contingency. Failure to control for the rate of US presentation in previous studies of the effect of CS-US contingency on fear conditioning has led to the unsubstantiated conclusion that CS-US contingency is fundamental to classical conditioning.
\end{abstract}

It is now widely accepted that classical conditioning depends not only on the temporal contiguity of conditioned stimulus (CS) and unconditioned stimulus (US), but also on the CS-US correlation or contingency. With the contiguity, or joint occurrence, of CS and US held constant, CS-US contingency is weakened either by presentations of CS alone or by presentations of US alone. A commonly used index of contingency is given by the difference between conditional probabilities: the probability of US given CS, or P(US/CS), and the probability of US in the absence of CS, P(US/no CS). The contingency is positive when $\mathrm{P}(\mathrm{US} / \mathrm{CS})$ is greater than $\mathrm{P}(\mathrm{US} /$ no CS $)$, negative when the reverse is true, and zero when the probabilities are equal. Mackintosh (1974) expressed the prevailing view of the importance of contingency for conditioning when he wrote: "conditioning experiments can be operationally defined as arrangements of correlations or contingencies between events .... The most natural interpretation ... is that animals detect these contingencies: exposed to these particular relationships they learn to associate these correlated events" (p. 244). The results of the present experiment question this conclusion.

The idea that contingency is fundamental to conditioning owes much to the work of Rescorla. In an influential paper on the proper control for classical conditioning, Rescorla (1967) argued that only those behavioral changes that depend on CS-US contingency should be regarded as conditioned. Accordingly, a noncontingent CS-US sequence is the proper control for classical conditioning, even though that sequence will generally include some contiguous presentations of

This research was supported by a grant to the first author from the National Science and Engineering Research Council of Canada. The results were presented at the meeting of the Psychonomic Society, St. Louis, Missouri, November 1980. Requests for reprints should be sent to H. M. Jenkins, Department of Psychology, McMaster University, Hamilton, Ontario L8S 4K1 Canada.
CS and US. Shortly thereafter, Rescorla (1968) reported an experiment on fear conditioning in which he found a close relation between the degree of CS-US contingency and the strength of conditioning to the CS, as measured by response suppression in the conditioned emotional response (CER) procedure. Subsequently, a theory of classical conditioning presented by Rescorla and Wagner (1972) provided an explanation for the dependence of conditioning on contingency. Although the theory did not assume that contingency was necessary for conditioning, it nevertheless showed how a trial-by-trial conditioning process could produce the close relation between CS-US contingency and the asymptotic strength of conditioning that was found in Rescorla's (1968) earlier CER experiment. Thus, both empirical and theoretical developments have led to the view that CS-US contingency is a fundamental determinant of the acquisition of signal value by the CS in the classical conditioning experiment.

Although the kind of evidence we have cited shows that more than CS-US contiguity is involved in the acquisition of signal value, it does not in fact show that contingency best expresses the property of the CS-US sequence underlying classical conditioning. Consider a conditioning regimen consisting entirely of a certain number of joint CS-US presentations. If unsignaled USs (USs unaccompanied by CSs) were now added, the altered sequence would be expected to produce poorer conditioning. Such a result is sufficient to show that more is involved than CS-US contiguity, since contiguity would be unchanged by the addition of unsignaled USs. Although the added USs would reduce CS-US contingency, it could not be concluded that reduced contingency was the cause of poorer conditioning. The added USs change another property of the sequence that might also weaken conditioning; specifically, they increase the rate at which USs occur. Even if the added USs were each signaled by CSs, so that CS-US contingency was unchanged, the increase in the US rate, which 
in this instance would amount to a decrease in the intertrial interval, would be expected to yield poorer conditioning. Such effects have been shown in autoshaping (e.g., Gibbon, Baldock, Locurto, Gold, \& Terrace, 1977), in the CER (Stein, Sidman, \& Brady, 1958), and in other varieties of classical conditioning (Mitchell, 1973; Prokasy \& Ebel, 1964). Therefore, before concluding that the introduction of unsignaled USs reduces conditioning because it reduces CS-US contingency, it is necessary to show that the addition of unsignaled USs is more damaging to acquisition than is the addition of signaled USs (cf. Gibbon et al., 1977).

The present experiment provides the needed comparison. The groups in Rescorla's (1968) CER experiment on contingency were replicated: a strongly contingent group that received no unsignaled USs and a less contingent group in which the contingency was reduced by the addition of unsignaled USs with a consequent increase in the US rate. A control group was added that also received the higher US rate, but in which all USs were signaled so that no reduction in contingency was involved.

\section{METHOD}

\section{Subjects}

Male hooded rats, housed in individual cages under a 12-h light-dark cycle, were maintained by restricted feeding at approximately $80 \%$ of their free-feeding weights. Data were obtained from 18 rats out of an initial group of 24 ; data from the other 6 rats were unusable due to a malfunction in one of the experimental chambers.

\section{Apparatus}

Each of four aluminum lever boxes, $31 \times 21 \times 21 \mathrm{~cm}$, with electrifiable grid floors was enclosed in its own sound-attenuating outer shell, $37 \times 51 \times 34 \mathrm{~cm}$. Centered on the end wall of the lever box, near the floor, was a small food hopper into which a pellet dispenser delivered a $45-\mathrm{mg}$ Noyes rat pellet. A retractable lever was mounted to the left of the hopper. Also mounted on the end wall were two miniature bulbs, with white jeweled caps, which lighted the box. The CS was provided by an audio oscillator that fed a small speaker mounted within the soundattenuating outer enclosure. The floor of the lever box consisted of $5-\mathrm{mm}$ stainless steel rods spaced $14 \mathrm{~mm}$ apart. The rods could be electrified by a Lehigh Valley constant-current shock generator (Model 113-04) that was wired to the rods through a shock-scrambling circuit. White masking noise was supplied to the experimental room. Equipment for automatic control and data recording was located in a separate room.

\section{Design and Procedure}

The basic parameters for training and testing procedures were those used by Rescorla (1968, Experiment 2). Subjects were shaped to barpress for food and were then placed on a variable interval (VI) 1 -min reinforcement schedule for one 2-h session. Four additional 2-h sessions on a VI 2-min schedule completed barpress training. This was followed by five 2 -h Pavlovian fear conditioning sessions that were carried out in the lever boxes with the levers retracted. The CS was a 2-min presentation of a $1,000-\mathrm{Hz}$ tone at $85 \mathrm{~dB}$, as measured by a soundlevel meter (General Radio, Type 1551-C, B-scale). The shock was $.5 \mathrm{sec}$ in duration at $.9 \mathrm{~mA}$.

Six subjects were assigned to each of three treatment conditions so as to match the groups as closely as possible on the basis of their mean barpressing rates. Treatments during Pavlovian
Table 1

Parameters of CS-US Presentations per Session for Groups

\begin{tabular}{cccccr}
\hline \multicolumn{2}{c}{ Group } & \multicolumn{5}{c}{$\begin{array}{c}\text { Shock } \\
\text { Probability }\end{array}$} \\
$\begin{array}{ccccc}\text { Contin- } \\
\text { gency }\end{array}$ & $\begin{array}{c}\text { US } \\
\text { Rate }\end{array}$ & $\begin{array}{c}\text { Number } \\
\text { of CSs }\end{array}$ & CS & Non-CS & E \\
\hline High & Low & 12 & .4 & .0 & 4.8 \\
Low & High & 12 & .4 & .2 & 14.4 \\
High & High & 36 & .4 & .0 & 14.4 \\
\hline
\end{tabular}

Note $-E=$ expected total number of shocks.

conditioning are shown for each group in Table 1. The shock probability is per a 2-min period of the CS or non-CS. The expected total number of shocks is based on both CS and non-CS periods. The first two groups shown in Table 1 correspond to two of the groups run by Rescorla (1968, Experiment 2). Compared with the first group, the second group had both a lower CS-US contingency and a higher mean rate of US presentation. The third group had the same high contingency as the first group and the same high US rate as the second group.

The 2-min CS presentations were assigned entirely at random to the $602-\mathrm{min}$ intervals in each $2-\mathrm{h}$ session. The event sequence for the second group was derived from that of the third group by removing at random 24 of the $36 \mathrm{CS}$ presentations, thereby resulting in shocks in non-CS periods. The event sequence for the first group was derived from that of the second by eliminating the non-CS shocks. The last column of Table 1 shows the expected total number of shocks per session. The actual schedule of shocks was obtained by setting a constant probability of shock in each $1-\mathrm{sec}$ interval of the CS or non-CS. This generated a different random distribution of shocks for each session.

Following the Pavlovian conditioning sessions, two further sessions of operant barpress training on the VI 2-min reinforcement schedule were given in order to restore a stable rate of barpressing. Five test sessions followed. In each test session, four 2-min tone CSs were randomly presented with a minimum $5-\mathrm{min}$ intertrial interval and mean interval of $30 \mathrm{~min}$. No shocks were delivered in test sessions. Reinforcement for barpressing continued without change.

Conditioning to the $\mathrm{CS}$ was assessed by means of a suppression ratio of the form $A /(A+B)$, where $A$ is the number of responses during the $2-\mathrm{min} C S$ and $B$ is the number of responses in the $2-\mathrm{min}$ period immediately preceding the CS. Complete cessation of responding in CS yields a suppression ratio of 0 (maximum suppression). No change in responding due to $\mathrm{CS}$ yields a value of .5 (no suppression).

\section{RESULTS AND DISCUSSION}

There were no significant (or suggestive) differences in the baseline or pre-CS rates of barpressing across groups, during either the barpress retraining sessions or the test session. Although this is surprising in view of the unsignaled shocks received in the group conditioned with low contingency and high US rate, Rescorla (1968) also reported no significant differences in base rates despite the occurrence of unsignaled shocks in some groups.

Only the first test session provided informative results; thereafter, the CS rapidly lost its suppressive effect in all groups. Figure 1 shows results for the suppression ratio for each trial of the first test session and the mean suppression ratios. The group conditioned with high contingency and low US rate showed significantly greater mean suppression over the four test 


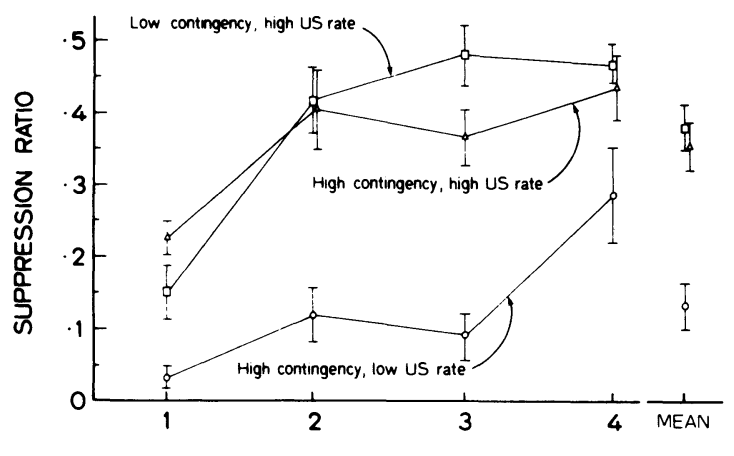

TRIAL NUMBER

Figure 1. Suppression ratio as a function of trials during the first test session. Mean of the four trials for each group is shown at the right. Bars show 1 standard error of the mean.

trials than did either of the other two groups ( $p<.05$ by two-tailed $U$ tests for each comparison). The other two groups did not differ significantly $(\mathrm{p}>.4)$.

These results show that the reduction in the amount of conditioned suppression due to an increase in the US rate did not depend on whether the increased US rate resulted from the addition of signaled or unsignaled USs. Another way to express this result is to note that lowering the percent of USs that were signaled did not reduce the level of conditioning. A similar result has been found in autoshaping of the pigeon's keypeck with food reinforcers (Jenkins, Barnes, \& Barrera, in press). No significant effect on the level of autoshaped keypecking was found, despite variations in the percent of feedings that were signaled ranging from $100 \%$ to $3 \%$. If conditioning is not adversely affected by severe reductions in the percent of USs that are paired with CSs, then it is not CS-US contingency that underlies the acquisition of signal strength in Pavlovian conditioning.

Extensive data on the relation of autoshaping to properties of the CS-US sequence have led Gibbon (in press) and Jenkins et al. (in press) to propose an alternative to CS-US contingency. Jenkins has referred to this proposal as the relative waiting time hypothesis. It asserts that a critical parameter for the acquisition of signal strength in classical conditioning is the ratio of the average waiting time in the CS per US to the overall average waiting time per US in the experimental setting. In the completely noncontingent case, waiting time in the CS is equal to overall waiting time and little or no conditioning is expected. Within broad limits, the shorter the waiting time in the CS relative to the overall waiting time, the more favorable is the CS-US sequence for conditioning. The overall waiting time for the US in the experimental setting is determined, according to the hypothesis, by the average US rate, without regard for the stimulus conditions that accompany the US; signaled and unsignaled USs contribute equally to the overall US waiting time. Thus, according to this hypothesis, the percentage of USs that are signaled by the CS is not an effective variable. For a given waiting time in the CS, the strength of conditioning resulting from a CS-US pairing would depend on the average time between US presentations whether these presentations are signaled or unsignaled.

The present results are consistent with the relative waiting time hypothesis. Suppression in the highcontingent/high-US-rate condition was no different from that in the low-contingent/high-US-rate condition. Although these conditions differ in CS-US contingency, they have the same waiting time per shock in the CS and the same overall waiting time between shocks. They should therefore yield equivalent conditioning according to the hypothesis. The stronger conditioning found in the high-contingency/low-US-rate condition is, according to the hypothesis, the result of a longer overall mean waiting time per shock in the experimental setting.

The relative waiting time hypothesis is also consistent with results reported by Stein et al. (1958) on the effects of CS and non-CS durations on conditioned suppression. In their experiment, CER conditioning was superimposed on food-reinforced barpressing (on the baseline procedure). The authors offered an explanation for their results based on the loss of food reinforcement that would be incurred by the complete suppression of barpressing during CS as a function of the durations of CS and non-CS. The product-moment correlation of asymptotic suppression levels for 20 different CS and non-CS durations with the hypothetical food loss was +.92. However, we find that the correlation of suppression levels in their experiment with the ratio of waiting times is also +.92 . Moreover, the relative duration of CS and non-CS periods has been shown to have a similar effect in autoshaping (Gibbon et al., 1977; Gibbon, Locurto, \& Terrace, 1975; Perkins, Beavers, Hancock, Hemmendinger, Hemmendinger, \& Ricci, 1975; Terrace, Gibbon, Farrell, \& Baldock, 1975), for which the lost-food explanation is inapplicable.

The results reported by Rescorla (1968) on the effect of varying the probability of shock in the presence and absence of the CS have provided the strongest empirical support for the view that CS-US contingency underlies the acquisition of signal strength. The amount of conditioned suppression was found to vary with the difference between the shock probabilities in CS vs. non-CS periods; in other words, it varies with the degree of positive CS-US contingency. The Rescorla-Wagner theory provides a theoretical explanation for the effect of contingency from which the rank order of the groups in Rescorla's experiment, based on asymptotic levels of suppression, can be predicted. We find the rank-order correlation between predicted and obtained suppression ratios to be .93 . However, the relative waiting time hypothesis does as well, yielding a correlation of .98 .

Equivalent interference with conditioning from the addition of signaled or unsignaled shock appears to contradict the Rescorla-Wagner theory. In the theory, the asymptotic level of fear conditioning would not be reduced by the addition of signaled shocks, but it 
would be reduced by unsignaled shocks because they maintain excitatory fear conditioning to the background. The effect of signaled vs. unsignaled shock on the course of preasymptotic acquisition is, however, dependent in the theory on the relative salience of background and CS. If the background were assumed to be far more salient than the CS, signaled and unsignaled shocks would have similar effects early in acquisition. Although in the present experiment we used the same number and duration of fear conditioning sessions (five 2-h sessions) as did Rescorla (1968), it remains possible that conditioning was not carried out long enough for effects of signaled and unsignaled shocks to diverge (Rescorla, Note 1).

The certain conclusion from the present experiment is that the evidence that has been taken to demonstrate a critical role of CS-US correlation in classical conditioning is open to another interpretation. In order to test for the role of CS-US correlation in classical conditioning, it will be necessary to show that the correlation is effective when the US rate and the waiting time for US in $\mathrm{CS}$ relative to the overall waiting time are unconfounded with CS-US correlation.

\section{REFERENCE NOTE}

1. Rescorla, R. A. Personal communication, November 13, 1980.

\section{REFERENCES}

GibBon, J. The contingency problem in autoshaping. In C. M. Locurto, H. S. Terrace, \& J. Gibbon (Eds.), Autoshaping and conditioning theory. New York: Academic Press, in press.

Gibbon, J., Baldock, M., Locurto, C., Gold, L., \& Terrace, H. S. Trial and intertrial durations in autoshaping. Journal of Experimental Psychology: Animal Behavior Processes, 1977, 3, 264-284.
Gibbon, J., Locurto, C., \& Terrace, H. S. Signal-food contingency and signal frequency in a continuous trials auto-shaping paradigm. Animal Learning \& Behavior, 1975, 3, 317-324.

Jenkins, H. M., Barnes, R. A., \& Barrera, F. J. Why autoshaping depends on trial spacing. In C. M. Locurto, H. S. Terrace, \& J. Gibbon (Eds.), Autoshaping and conditioning theory. New York: Academic Press, in press.

Mackintosh, N. J. The psychology of animal learning. New York: Academic Press, 1974.

Mitchell, D. S. Trial distribution effects on postasymptotic performance and retention of the rabbit's (Oryctolagus cuniculus) classically conditioned nictitating membrane response. Journal of Comparative and Physiological Psychology, 1973, 83, 346350.

Perkins, C. C., Beavers, W. O., Hancock, R. A., Hemmendinger, P. C., Hemmendinger, D., \& Ricci, J. A. Some variables affecting rate of key pecking during responseindependent procedures (autoshaping). Journal of the Experimental Analysis of Behavior, 1975, 24, 59-72.

Prokasy, W. F., \& Ebel, H. C. GSR conditioning and sensitization as a function of intertrial interval. Journal of Experimental Psychology, 1964, 67, 113-119.

Rescorla, R. A. Pavlovian conditioning and its proper control procedures. Psychological Review, 1967, 74, 71-80.

Rescorla, R. A. Probability of shock in the presence and absence of CS in fear conditioning. Journal of Comparative and Physiological Psychology, 1968, 66, 1-5.

Rescorla, R. A., \& Wagner, A. R. A theory of Pavlovian conditioning: Variations in the effectiveness of reinforcement and nonreinforcement. In A. H. Black \& W. F. Prokasy (Eds.), Classical conditioning II: Current research and theory. New York: Appleton-Century-Crofts, 1972.

Stein, L., Sidman, M., \& Brady, J. V. Some effects of two temporal variables on conditioned suppression. Journal of the Experimental Analysis of Behavior, 1958, 1, 153-162.

Terrace, H. S., Gibbon, J., Farrell, L., \& Baldock, M. D. Temporal factors influencing the acquisition of an autoshaped key peck. Animal Learning \& Behavior, 1975, 3, 53-62.

(Received for publication January 30, 1981.) 